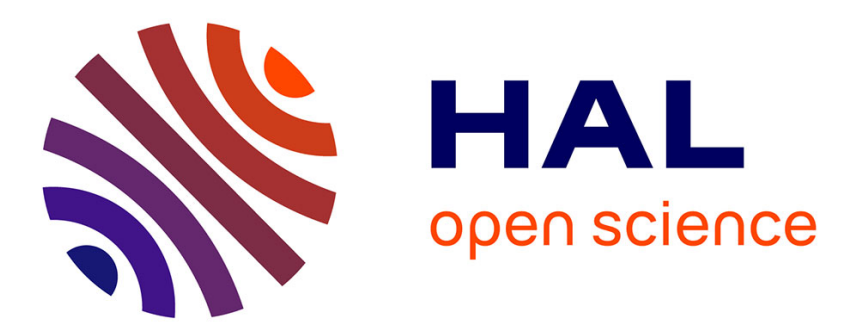

\title{
Inhibitors of NQO1: Identification of compounds more potent than dicoumarol without associated off-target effects
}

Katherine Ann Scott, John Barnes, Roger Clive Whitehead, Ian James Stratford, Karen Ann Nolan

\section{To cite this version:}

Katherine Ann Scott, John Barnes, Roger Clive Whitehead, Ian James Stratford, Karen Ann Nolan. Inhibitors of NQO1: Identification of compounds more potent than dicoumarol without associated off-target effects. Biochemical Pharmacology, 2010, 81 (3), pp.355. 10.1016/j.bcp.2010.10.011 . hal00654979

\section{HAL Id: hal-00654979 \\ https://hal.science/hal-00654979}

Submitted on 24 Dec 2011

HAL is a multi-disciplinary open access archive for the deposit and dissemination of scientific research documents, whether they are published or not. The documents may come from teaching and research institutions in France or abroad, or from public or private research centers.
L'archive ouverte pluridisciplinaire HAL, est destinée au dépôt et à la diffusion de documents scientifiques de niveau recherche, publiés ou non, émanant des établissements d'enseignement et de recherche français ou étrangers, des laboratoires publics ou privés. 


\section{Accepted Manuscript}

Title: Inhibitors of NQO1: Identification of compounds more potent than dicoumarol without associated off-target effects

Authors: Katherine Ann Scott, John Barnes, Roger Clive Whitehead, Ian James Stratford, Karen Ann Nolan

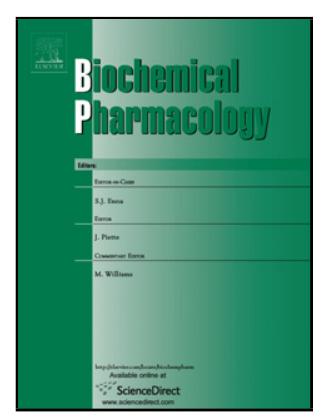

PII:

S0006-2952(10)00767-7

DOI: doi:10.1016/j.bcp.2010.10.011

Reference: BCP 10743

To appear in: $\quad B C P$

Received date: $\quad$ 23-7-2010

Revised date: $\quad 13-10-2010$

Accepted date: $\quad 14-10-2010$

Please cite this article as: Scott KA, Barnes J, Whitehead RC, Stratford IJ, Nolan KA, Inhibitors of NQO1: Identification of compounds more potent than dicoumarol without associated off-target effects, Biochemical Pharmacology (2010), doi:10.1016/j.bcp.2010.10.011

This is a PDF file of an unedited manuscript that has been accepted for publication. As a service to our customers we are providing this early version of the manuscript. The manuscript will undergo copyediting, typesetting, and review of the resulting proof before it is published in its final form. Please note that during the production process errors may be discovered which could affect the content, and all legal disclaimers that apply to the journal pertain. 
Inhibitors of NQO1: Identification of compounds more potent than dicoumarol without associated off-target effects

Katherine Ann Scott ${ }^{\mathrm{a}}$, John Barnes ${ }^{\mathrm{a}, \mathrm{b}}$, Roger Clive Whitehead ${ }^{\mathrm{b}}$, Ian James Stratford ${ }^{\mathrm{a}}$ and Karen Ann Nolan $^{\mathrm{a} *}$

${ }^{a}$ School of Pharmacy and Pharmaceutical Sciences, University of Manchester and

Manchester Cancer Research Centre, Manchester, Oxford Road, Manchester, M13 9PT, UK.

${ }^{b}$ School of Chemistry, University of Manchester, Oxford Road, Manchester, M13 9PT, UK.

*To whom correspondence should be addressed. Tel: +44-(0)161-275-5634. Fax: +44-(0)161-

275-8342. Email: Karen.Nolan-2@manchester.ac.uk (K.A. Nolan) 


\begin{abstract}
The enzyme $\mathrm{NAD}(\mathrm{P}) \mathrm{H}$ quinone oxidoreductase (NQO1) can function both as a detoxifying enzyme as well as chaperone protein. The latter property has been extensively characterized by the use of dicoumarol which inhibits the chaperone properties of NQO1 in cells. However, the use of this compound is compromised by its multiple "off-target" effects. Coumarin-based compounds that are more potent than dicoumarol as inhibitors of NQO1 in cells have been identified (Nolan et al., Biochem Pharmacol 2010;80:977-81). The purpose of the work reported here is to evaluate the off-target effects of these compounds when compared to dicoumarol. A range of these substituted coumarins are identified that are significantly less toxic than dicoumarol in a panel of nine cell lines. Further a number of the compounds generate much less intracellular superoxide, and many of them also show a reduced ability to induce apoptosis when compared to dicoumarol. None of these effects correlate with the ability of the compounds to inhibit the enzymatic activity of NQO1 in cells. In conclusion, potent inhibitors of NQO1 have been identified that will be more pharmacologically useful than dicoumarol for probing the function of NQO1 in cells and tissues.
\end{abstract}

Keywords : NQO1, Dicoumarol, Coumarins, Superoxide, Apoptosis 


\section{Introduction}

Human NAD(P)H quinone oxidoreductase (NQO1, DT-diaphorase, Quinone Reductase 1, Vitamin K Reductase, E.C.1.6.99.2.) is a flavoprotein with 274 residues per monomer and a molecular mass of 30,867 Da. NQO1 exists as a homodimer with one molecule of noncovalently bound flavin adenine dinucleotide (FAD) per monomer [1]. It has two active sites, which catalyse the obligate two-electron reduction of quinones, quinone epoxides and quinone-imines to hydroquinones [2]. The enzyme is unusual in that it has the capacity to utilise both the pyrimidine nucleotides NADH and NADPH, without preference, as reducing co-substrates [3]. The catalytic cycle of NQO1 functions via a "ping-pong" mechanism in two distinct steps: hydride transfer from the $\mathrm{NAD}(\mathrm{P}) \mathrm{H}$ to the FAD cofactor, followed by release of $\mathrm{NAD}(\mathrm{P})^{+}$and hydride transfer from the reduced cofactor to the quinone substrate [4]. This two electron reduction mechanism also means that NQO1 has antioxidant properties, as it will prevent reduction of quinones by one-electron reductases. The latter would cause the formation of semiquinones with concomitant formation of reactive oxygen species [2].

An additional function of NQO1 is its clear ability to act as a chaperone protein. It has been described as the "gate keeper" of the 20S proteosome [5] and regulates the degradation of certain onco-proteins such as p53, p73 $\alpha$ and ornithine decarboxylase and proteins important in the regulation of mRNA translation [6,7]. The ability of NQO1 to stabilize proteins is dependent upon NADH [8] which suggests that the binding of the enzyme to its client protein(s) is most efficient when the protein FAD is in its reduced form. The anticoagulant dicoumarol (3,3'-methylenebis(4-hydroxycoumarin), has historically been regarded as the most potent inhibitor of NQO1 [9]; it acts through competitive binding with $\mathrm{NAD}(\mathrm{P}) \mathrm{H}$ and 
prevents the two-electron transfer to FAD from occurring [10]. Hence, addition of dicoumarol to cells has been shown to target p53 and other client proteins for degradation $[6-8,11,12]$.

NQO1 is constitutively expressed in a variety of tissues throughout the body, but is overexpressed in many solid tumours $[13,14]$. These observations have made NQO1 a potential target for the activation of certain bioreductive anticancer agents [15] such as mitomycin C [16], EO9 (5-aziridinyl-3-hydroxymethyl-2-(3-hydroxyprop-1-enyl)-1methylindole-4,7-dione) [17], streptonigrin [18], RH1 ((2,5-diaziridinyl-3-(hydroxymethyl)6-methyl-1,4-benzoquinone) [19] and $\beta$-lapachone [20].

Dicoumarol is often used as a pharmacological inhibitor to study the function of NQO1 in cells. This has not only been to establish the importance of the enzyme for the activation of bioreductive drugs [21, 22], but also to identify the importance of NQO1 for determining protein stability [23]. However, the actions of dicoumarol are compromised by extensive protein binding [24] and confounding "off-target" effects such as mitochondrial uncoupling $[25,26]$ and the increased production of intracellular superoxide $[27,28]$. These off-target effects can interfere with the interpretation of the function of NQO1 in cells. An example is where dicoumarol-induced production of superoxide was thought to be the basis for toxicity towards pancreatic cancer cells and this phenomena was considered to be NQO1 dependent $[29,30]$. However, different research group have subsequently presented data to show that these observations are not solely due to the inhibition of NQO1 but more importantly due to other properties of dicoumarol $[28,31,32]$. Thus, it is therefore of interest to develop novel inhibitors of NQO1 which retain the NQO1 inhibitory potency of dicoumarol but lack its unfavourable off-target effects. 
The synthesis of a series of novel substituted coumarin-based compounds with improved inhibitory potency in both isolated enzyme systems and cells has recently been reported [28, 33, 34]. This series of compounds have now been evaluated for their "off-target" effects when compared with dicoumarol. This paper provides an evaluation of the toxicity of these compounds in vitro, effects on cell cycle, and their abilities to cause apoptosis and generate superoxide. The major aim of the study was to identify compounds that may be more pharmacologically acceptable than dicoumarol; these will be compounds that have a similar or greater NQO1 inhibitory potency to dicoumarol, but have a lower level of cellular toxicity and fewer off-target effects.

\section{Materials and Methods}

\subsection{Reagents, chemicals and NQO1 inhibitors}

Unless otherwise stated, all reagents and chemicals were supplied by Sigma Aldrich (Poole, Dorset, UK). The NQO1 inhibitors have been previously described [28, 33, 34]. They comprise two series of substituted coumarins. The first includes a set of substituted dicoumarol analogues (the symmetric, $\mathbf{S}$ series, where dicoumarol is designated $\mathbf{S 1}$ ). The second group of compounds have one of the 4-hydroxycoumarol rings replaced by an aromatic ring system (the asymmetric, $\mathbf{A S}$ series). Structures are given in Figure 1 and Table 1. The compounds were dissolved in either DMSO (Fisher Scientific, Leicestershire, UK) or $0.13 \mathrm{M} \mathrm{NaOH}$ (VWR, Leicestershire, UK) to give a final concentration of $25 \mathrm{mM}$. 


\subsection{Cell lines and cell culture}

Human carcinoma cells with varying levels of NQO1 expression were selected for use. Cell lines were maintained at $37^{\circ} \mathrm{C}$ in a humidified incubator with an atmosphere of air plus $5 \%$ $\mathrm{CO}_{2}$. All cell lines were grown in RPMI-1640 medium (Invitrogen, Paisley, UK) supplemented with 10\% (v/v) heat-inactivated foetal calf serum (FCS) (Biosera, East Sussex, UK) and 2mM L-glutamine (Invitrogen, Paisley, UK), except MIA PaCa-2 cells which were grown in Dulbecco's Modified Eagle Medium (DMEM) (Invitrogen, Paisley, UK) supplemented with 10\% (v/v) FCS, 2.5\% (v/v) horse serum (Invitrogen, Paisley, UK) and 2mM L-glutamine. In the experiments using the MDA-MB-231, MDA-MB-468 and T47D cells which had been stably transfected with NQO1 (designated-DTD) [35], puromycin was added to the culture medium at a concentration of $5 \mu \mathrm{g} / \mathrm{ml}$ in order to maintain selection.

\subsection{Determining the activity of $\mathrm{NQO1}$ in cells}

Cells at a concentration of $1.5 \times 10^{5}$ were seeded into $10 \mathrm{~cm}$ dishes and left to reach approximately 70\% confluence. They were then washed in PBS (OXOID, Hampshire, UK) and scraped into phosphate buffer $(\mathrm{pH} 7.5)$ containing $5 \mu \mathrm{M}$ FAD and $250 \mathrm{mM}$ sucrose. The cells were sonicated twice for 5 seconds on ice, centrifuged at 13,000rpm $(16,200 \mathrm{~g})$ for 15 minutes at $4{ }^{\circ} \mathrm{C}$, and the supernatants collected and stored at $-80^{\circ} \mathrm{C}$. Protein concentrations were determined using the Bicinchoninic acid (BCA) protein assay [36]. The assay for NQO1 enzyme activity has been described previously [28]. Briefly, 10 $\mu 1$ of cell lysate was mixed with $490 \mu \mathrm{l}$ of $50 \mathrm{mM}$ phosphate buffer at $\mathrm{pH} 7.5$ containing $200 \mu \mathrm{M} \mathrm{NADH}, 70 \mu \mathrm{M}$ cytochrome c and $20 \mu \mathrm{M}$ menadione. Reactions were carried out at $25^{\circ} \mathrm{C}$ and cytochrome $\mathrm{c}$ reduction was followed at 550nm in a Beckman DU650 spectrophotometer. Dicoumarol 
$(100 \mu \mathrm{M})$ was added to a parallel reaction mixture and the difference in the rates of reaction in the presence and absence of dicoumarol was then used to define the activity of NQO1 in the cellular lysates.

\subsection{Assays of toxicity}

The MTT proliferation assay [37] was used as a surrogate measure of the toxicity of the dicoumarol analogues. Cells were seeded at $7.5 \times 10^{3}$ cells/well into 96-well plates and were exposed to increasing concentrations of dicoumarol (S1) or each inhibitor from the $\mathbf{S}$ and $\mathbf{A S}$ series for 96 hours. The number of surviving cells was then determined using the MTT assay. MTT (3-(4,5-dimethylthiazol-2-yl)-2,5-diphenyltetrazolium bromide) was dissolved in sterile PBS and added to the wells at a final concentration of $1.5 \mathrm{mM}$. Cells were incubated with MTT for 4 hours, at which time the resulting formazan crystals were solubilised with DMSO and absorbance read at $540 \mathrm{~nm}$. Values of $\mathrm{IC}_{50}$ were calculated as the drug concentration required to reduce optical density by $50 \%$ relative to vehicle treated control cells.

In some experiments, A549 or MIA PaCa-2 cells were treated with EO9 (Apaziquone, synthesized in-house) with and without various non-toxic concentrations of the $\mathbf{S}$ and $\mathbf{A S}$ compounds for 3 hours. EO9 and the compounds were then removed and cells left in growth medium for 96 hours prior to addition of MTT for assessment of toxicity. As this has been described in detail previously [34], the ability of the putative enzyme inhibitors to protect against the toxicity of EO9 in cells is a surrogate measure for their ability to inhibit cellular NQO1. 


\subsection{Intracellular superoxide production}

MIA PaCa-2 and MDA-MB-231 wild-type (WT) and DTD cells were grown to approximately $70 \%$ confluence, harvested using trypsin/EDTA, and $1 \times 10^{6}$ cells were resuspended in $1.5 \mathrm{ml}$ culture media in $5 \mathrm{ml}$ tubes. Dicoumarol or the other $\mathbf{S}$ and $\mathbf{A S}$ compounds were added to the cells (at varying concentrations up to $400 \mu \mathrm{M}$ ) and incubated for 4 hours, with agitation every 20 minutes. Dihydroethidium was then added to each tube to give a final concentration of $10 \mu \mathrm{M}$. The cells were incubated for another 30 minutes, centrifuged and the cell pellets were resuspended in $1 \mathrm{ml}$ ice-cold PBS. Samples were kept on ice and analysed immediately on a CyanADP flow cytometer using the Summit software package (Dako, Colorado, USA). Dihydroethidium is oxidised to 2-hydroxyethidium by superoxide, which then intercalates DNA and fluoresces red. This signal has been suggested to report the formation of intracellular superoxide [38]. The oxidized product, 2hydroxyethidium, was excited by blue light (488nm, argon laser) and fluorescence was measured using a 613/20 bandpass filter. The use of dihydroethidium is considered to be a relatively specific method for measuring superoxide [38]. However, it can be oxidized by other agents such as hydrogen peroxide in the presence of haem containing proteins [39]. These oxidation reactions can result in the production of different oxidation products with excitation and emission spectra overlapping with that of 2-hydroxyethidium [26]. Thus, to confirm that oxidation of dihydroethidium occurred via reaction with superoxide, experiments were carried out in the presence of ambroxol (2-amino-3,5-dibromo-N-[trans-4hydroxycyclohexyl] benzylamine). Ambroxol is a, so-called, superoxide, dismutase mimetic and has been used previously $[26,40]$ to confirm oxidation reactions occurring via superoxide. In all experiments, cells were exposed to $50 \mu \mathrm{M}$ menadione as a positive control for generation of superoxide. 


\subsection{Cell cycle analysis}

Cells were seeded into $10 \mathrm{~cm}$ dishes at a concentration of $1.5 \times 10^{5}$ cells per dish and left to adhere overnight. Cells were treated with $100,200,300$ or $400 \mu \mathrm{M}$ of dicoumarol $(\mathbf{S 1})$ or the $\mathbf{S}$ or AS compounds and incubated for 24 hours. The cells were harvested using trypsin/EDTA, washed in PBS and then resuspended in $1 \mathrm{ml}$ ice-cold $70 \%$ (v/v) ethanol added drop-wise while using a vortex mixer to avoid clumping. The cells were then left in ethanol at $4^{\circ} \mathrm{C}$ for a minimum of 24 hours. For cell cycle analysis, the cells were washed twice in PBS and finally resuspended in $500 \mu \mathrm{l}$ of PBS containing propidium iodide (PI, $25 \mu \mathrm{g} / \mathrm{ml}$ ) and RNase A $(250 \mu \mathrm{g} / \mathrm{ml})$, and incubated at $37^{\circ} \mathrm{C}$ in the dark for 30 minutes. Cells were then washed and resuspended in 500 $\mu 1$ PBS and kept in the dark in preparation for analysis. Samples were analysed on a CyanADP flow cytometer using the Summit software package. Cell doublets were gated out using a plot of PI signal height against signal area and data was collected as histograms illustrating fluorescence intensity and hence DNA content of the cells. The percentage of cells in the different phases of the cell cycle were then calculated using gates positioned to encompass the respective phases of control cells in each individual experiment.

\subsection{Western blot analysis of apoptotic markers}

Exponentially growing cells were seeded into 6-well plates at a concentration of $1.5 \times 10^{5}$ cells per well and left overnight to adhere. Cells were treated with $200 \mu \mathrm{M}$ of dicoumarol (S1) or the $\mathbf{S}$ or $\mathbf{A S}$ compounds, incubated for 24 hours and then harvested by scraping into lysis buffer (50mM Tris-HCl (pH 7.4) (Fisher Scientific, Leicestershire, UK); 120mM NaCl; 5mM EDTA; $0.5 \%$ (v/v) Nonidet P-40; 1mM dithiothreitol; 1mM phenylmethanesulphonyl fluoride; $2 \mathrm{mM}$ sodium orthovanadate; $2 \mathrm{mM}$ sodium fluoride; $20 \mathrm{mM}$ B-glycerolphosphate; $5 \mathrm{mM}$ 
sodium pyrophosphate; and 1mg/ml Protease Inhibitor Cocktail tablet (Roche, Hertfordshire, UK). Samples were sonicated on ice and the protein concentration was estimated using the BCA protein assay. Protein $(40 \mu \mathrm{g})$ was loaded for each sample, resolved on a $10 \%$ polyacrylamide gel and then transferred to a polyvinylidene (PVDF) membrane (Millipore, Hertfordshire, UK). Immunoblotting was carried out using a 1:1000 dilution of the cleaved PARP antibody (New England Biolabs, HertfordshireUK; anti-rabbit) or a 1:40000 dilution of the actin antibody. Primary antibodies were detected using the correct horse radish peroxidise (HRP)-conjugated secondary antibody, and the ECL detection system (GE Healthcare, Buckinghamshire, UK) was used to visualise the respective bands.

\section{Results}

Novel analogues of dicoumarol (S1) have been synthesized (the $\mathbf{S}$ and $\mathbf{A S}$ series in Figure 1 and Table 1) and shown to be potent inhibitors of recombinant NQO1 [33]. These molecules also show potent activity for inhibiting the activity of NQO1 in HT29 cells, with potency correlating well with that observed when measuring inhibition of recombinant enzyme in the presence of BSA [34]. These published data are given in Table 1. Inhibition of cellular NQO1 was characterized by the ability of the $\mathbf{S}$ and $\mathbf{A S}$ compounds to inhibit the cytotoxic activity of the indolequinone EO9, an agent known to be exquisitely dependent on NQO1 for toxicity under aerobic conditions [21, 22]. Table 1 also shows the ability of the $\mathbf{S}$ and $\mathbf{A S}$ compounds to inhibit NQO1 in A549 and MIA PaCa-2 cells. Using the EO9 toxicity end-point as a surrogate measure of NQO1 inhibition, it is apparent that $\mathbf{S 3}$ is the most active compound in each cell line, being 2.5 to 10 -fold more potent than dicoumarol for protecting against EO9 toxicity. In the $\mathbf{S}$ series, $\mathbf{S 1 0}$ and $\mathbf{S 1 3}$ are up to 2-fold more efficient than dicoumarol (S1), whereas the remaining compounds are less effective. On the contrary, in the AS series, all the 
compounds are at least as efficient as dicoumarol, with some (AS2 and AS14) showing 2- to 4-fold greater potency in the different cell lines. With the knowledge that these compounds are functionally active as inhibitors of NQO1 in cells, it is now possible to assess any "offtarget" activity and relate this to NQO1 inhibition.

\subsection{The toxicity of the dicoumarol analogues in cell lines expressing varying levels of NQO1}

The activity of NQO1 in the cell lines used in the present work is given in Table 2. Cell lines were chosen to have varying NQO1 activity. The MDA-MB-231, MDA-MB-468 and T47D WT cells are null for NQO1 due to a homozygous polymorphism $(\mathrm{NQO} 1 * 2 / * 2)$ [41, 42, 43]. Each of these cell lines have been genetically engineered to stably overexpress functional NQO1 [35]. In order to evaluate any contribution of p53, the HCT116 $\mathrm{p}^{+/+} 3^{+-}$and $^{-/}$pair of cell lines were used [44]. The values for enzyme activity given in Table 2 vary by a factor of 250. Endogenous values of enzyme activity range from 20 to 3011 (nmoles of cytochrome c reduced / min / mg protein) in the MDA-MB-468 and A549 cells respectively. The maximum activity is 5284 in the overexpressing T47D DTD cells. Where measurements have been made previously, the values reported here compare extremely well [17]. It has been suggested [30] that the toxicity of dicoumarol is mediated by its ability to inhibit NQO1 thereby increasing cellular exposure to reactive oxygen species. Therefore, the toxicity of dicoumarol (S1) and analogues from the $\mathbf{S}$ and $\mathbf{A S}$ series were evaluated in all the cell lines. Values of $\mathrm{IC}_{50}$, the concentration required to reduce proliferation by 50\%, are given in Table 3 . Dicoumarol is consistently one of the most toxic compounds in all of the cell lines and it is clear that neither NQO1 nor p53-status plays a role in determining toxicity. There also appears to be no relationship between the toxicity induced by the compounds and their ability to inhibit NQO1enzymatic activity (Table 1). 


\subsection{Production of intracellular superoxide}

Dicoumarol has been shown to dose-dependently increase the production of superoxide in MIA PaCa-2 pancreatic cancer cells [27]. This result was recapitulated here using flow cytometry to measure the superoxide-mediated oxidation of dihydroethidium to 2hydroxyethidium. Figure 2 shows fluorescence intensity histograms acquired following treatment of MIA PaCa-2 cells with increasing concentrations of dicoumarol (S1) for 4 hours. In all experiments, $50 \mu \mathrm{M}$ menadione was used as a positive control for superoxide production [45]. From the fluorescence intensity profile obtained for untreated control cells, the R3 region is defined as that containing cells with increased fluorescence. Clearly, treatment with dicoumarol results in a dose-dependent increase in the number of fluorescent cells, which is consistent with previous data [27] suggesting it was dicoumarol-induced superoxide formation that caused the increased intracellular fluorescence. To confirm this, the superoxide dismutase mimetic, ambroxol, was added to the cells exposed to dicoumarol. Figure 2, panel $\mathrm{F}$, shows the fluorescence profile obtained when cells were exposed to the combination of $200 \mu \mathrm{M}$ dicoumarol plus $500 \mu \mathrm{M}$ ambroxol. This non-toxic combination shows little, if any, formation of the fluorescent product 2-hydroxyethidium, which suggests that any superoxide formed by a dicoumarol-mediated process is scavenged by ambroxol, thereby preventing reduction of dihydroethidium.

The $\mathbf{S}$ and $\mathbf{A S}$ compounds were then evaluated for their ability to generate superoxide in MIA PaCa- 2 cells. Figure 3 shows the percentage of cells with increased fluorescence relative to untreated controls, following exposure of cells to varying concentrations of the compounds. There is substantial variation in the ability of the compounds to generate superoxide and there appears to be no relationship with the ability of the different compounds to inhibit NQO1. 
However, interestingly, the compounds in the $\mathbf{S}$ series that contain a methoxy group in the coumarin ring $(\mathbf{S 3}, \mathbf{S 4}, \mathbf{S 5}$ and $\mathbf{S 1 1})$ and those in the $\mathbf{A S}$ series that contain the simpler Xsubstituent (AS3, AS6 and AS14) show substantially lower induction of superoxide than dicoumarol (S1) and the other compounds. This is reflected in an apparent correlation between superoxide production and the ability of the compounds to inhibit the proliferation of MIA PaCa-2 cells as measured by the MTT assay (Figure 4).

In order to confirm whether the phenomenon of intracellular superoxide production is not mediated by NQO1, measurements were made of changes in fluorescence intensity in the MDA-MB-231 WT and DTD cells, treated with a variety of compounds from the $\mathbf{S}$ and AS series. The cells were incubated for 4 hours with $100 \mu \mathrm{M}$ of each compound and the percentage of cells showing increased fluorescence relative to control is shown in Figure 5. Clearly, there is no significant difference in the generation of intracellular superoxide between the two cell lines for any of the compounds. It is also apparent that the same lack of dependence on NQO1 for superoxide production is seen for menadione (also shown in Figure $5)$.

\subsection{Effects on cell cycle progression and induction of apoptosis}

It has been shown previously that dicoumarol can promote the growth of HL-60 cancer cells via cell cycle perturbation [46]. In order to determine the effects of dicoumarol and the $\mathbf{S}$ and AS analogues on cell cycle progression, MIA PaCa- 2 cells were exposed to $200 \mu \mathrm{M}$ of each of the compounds for 24 hours before staining with propidium iodide for cell cycle analysis. Figure 6 shows typical DNA histograms of untreated cells and cells treated with dicoumarol (S1), S3 and AS2. Inspection of these profiles suggests that there is no substantive change in 
the percentage of cells in each of the phases of the cell cycle. However, for both dicoumarol and AS2 there is an indication of an increased number of cells in the sub-G1 region. The percentage of cells in each phase of the cell cycle following treatment with each compound is given in the Supplementary Data Table 1. The percentage of cells in the sub-G1 region following exposure to a $200 \mu \mathrm{M}$ concentration of each of the $\mathbf{S}$ and $\mathbf{A S}$ compounds is shown in the top panel in Figure 7. Clearly, there are significant differences, with compounds such as S3, S4, S5 and S11 (those showing low superoxide production) providing little if any increase in the sub-G1 population compared to controls. In contrast, the remaining compounds, including dicoumarol (S1) show significantly higher numbers of cells in the sub-G1 region than in untreated populations. In order to determine whether the cells in the sub-G1 region are undergoing apoptosis [47], cells were collected after 24 hour exposure to $200 \mu \mathrm{M}$ of dicoumarol and each of the $\mathbf{S}$ and $\mathbf{A S}$ compounds, cell lysates prepared and Western blots probed for cleaved PARP. These are shown in the bottom panel of Figure 7 and a clear concordance exists between expression of cleaved PARP and the percentage of cells in the sub-G1 area, which strongly suggests these cells are undergoing apoptosis. A comparison of the proportion of cells in the sub-G1 region and the generation of superoxide in MIA PaCa-2 cells treated with of each of the putative NQO1 inhibitors is given in the Supplementary Data Figure 1. While there is no correlation between these end-points, it is quite clear that the compounds generating high levels of superoxide are those that also seem to cause the greatest amount of apoptosis. However, importantly, there is no clear relationship between induction of apoptosis or generation of superoxide and the ability of the compounds to inhibit the enzymatic activity of NQO1 (Table 1). Finally, to confirm that there was no link between induction of apoptosis and cellular levels of NQO1, cell cycle analysis of the MDA-MB-231 WT and DTD cells was made following treatment for 24 hours with $200 \mu \mathrm{M}$ of dicoumarol (S1). The proportion of cells in the sub-G1 region following treatment is given in the 
Supplementary data Figure 2 and these results clearly show that the cellular NQO1 status has no influence on the number of cells in sub-G1.

\section{Discussion}

The purpose of this work has been to identify compounds that are potent inhibitors of NQO1 but with superior pharmacological acceptability than the conventional inhibitor, dicoumarol. A series of substituted coumarins has been synthesized (Figure 1 and Table 1) and many of these have equivalent or greater potency for inhibiting NQO1 than dicoumarol $[33,34]$. Further, these agents can also inhibit the functional activity of NQO1 in intact HT29 colon cancer, A549 non small cell lung cancer and MIA PaCa-2 pancreatic cancer cell lines [34]A number of these compounds (S3, S10, S13, AS2 and AS14) are consistently more potent than dicoumarol, which suggests they may have general applicability as NQO1 inhibitors in cells. It is known that dicoumarol has a variety of "off-target" effects that can confound interpretation of its action as an inhibitor of NQO1 in cells. Therefore, to establish the potential pharmacological usefulness of the substituted coumarins, experiments have been carried out to determine their toxicity in a large panel of cell lines, their ability to generate superoxide and their ability to cause apoptosis.

In the toxicity studies reported here, there is no relationship between the ability of the compounds to inhibit $\mathrm{NQO} 1$ and the values of $\mathrm{IC}_{50}$ in any of the cell lines (irrespective of the endogenous level of NQO1). Furthermore, there appears to be no dependence on p53 (HCT116 cells). Interestingly, dicoumarol is the most toxic agent in each cell line, irrespective of NQO1 content. For the other compounds there is no systematic relationship between structure and toxicity. In contrast, there are clear differences between the compounds 
for their ability to generate superoxide. Experiments were initially done in MIA PaCa-2 cells as these cells were used by $\mathrm{Du}$, Cullen and colleagues [27, 29, 30, 46] who initially proposed that dicoumarol generated superoxide via an NQO1-mediated mechanism. In the $\mathbf{S}$ series, compounds such as $\mathbf{S 1 0}$ and $\mathbf{S 1 3}$ are as efficient, if not more so, than dicoumarol for generating superoxide. These compounds are effective for inhibiting NQO1 in cells, but so is S3, and this compound generates little if any superoxide. A molecular feature of the compounds in the $\mathbf{S}$ series that do not generate superoxide is that they all contain a methoxy group in the coumarin ring. For the $\mathbf{A S}$ series, these compounds generally cause formation of superoxide. However, there are exceptions, with AS3 and AS6 generating substantially less superoxide than similar concentrations of dicoumarol; additionally, AS14, which is a more efficient inhibitor of NQO1 in cells than dicoumarol, generates little if any superoxide. Taken together with results showing similar superoxide production in isogenic cells expressing differing levels of NQO1 (MDA-MB-231 cells) and those in previous work reported by our group [28], and others [31, 32], these data strongly suggest that cellular NQO1 plays little if any role in the generation of superoxide in cells following treatment with dicoumarol and its analogues. However, the generation of superoxide may be the basis for the toxicity of the coumarin analogues as is suggested by the correlation shown in Figure 4. Interestingly, the relationship between superoxide production and apoptosis is less apparent, although it is quite clear that those compounds generating the greater amount of superoxide are those that produce most apoptosis.

Other off-target effects associated with dicoumarol include extensive protein binding and mitochondrial uncoupling. Protein binding has previously been shown [33] to be much reduced with some of the analogues, including S3. Further, preliminary experiments carried out to measure effects on oxygen respiration have shown that $\mathrm{S} 3$ shows a much reduced 
ability to cause mitochondrial uncoupling when compared to dicoumarol (Scott KA unpublished data).

It is not the purpose of this work to ascertain the underlying mechanism by which the coumarin analogues elicit their off-target effects. Instead, we are seeking to identify molecular features of compounds related to dicoumarol that would help facilitate their development as pharmacological inhibitors of NQO1. It is particularly obvious that the 5-methoxy substituted analogue of dicoumarol, $\mathbf{S 3}$, is the most potent inhibitor of NQO1 in cells, while being consistently less toxic in the nine cell lines used here. $\mathbf{S 3}$ also shows much reduced generation of superoxide and does not induce apoptosis. From the AS series, AS3 and AS14 stand out, as they also show comparable NQO1-inhibitory potency to dicoumarol in cells with generally less generation of superoxide, less apoptosis and reduced toxicity. A potential advantage of the AS compounds compared to their $\mathbf{S}$ analogues is their improved water solubility [33]. Thus, we have provided a firm basis for development of compounds to evaluate the impact of NQO1 inhibition in cells.

Using gene knockout technology it has been shown that loss of NQO1 is associated with reduced p53 stability [48, 49] and changes in NFkB signalling [50]. Treatment of cells with dicoumarol can also cause degradation of p53 and other onco-proteins in a process that is mediated by NQO1. There is good evidence to show that transient disruption of p53 during and after irradiation can protect against radiation damage [51, 52]. Thus, there may well be substantial scope for developing NQO1 inhibitors for therapeutic use [34]. In summary, it has been shown that there are a number of compounds that act as potent inhibitors of NQO1 and, beneficially, they lack the off-target effects associated with dicoumarol. 


\section{Acknowledgements}

This work was funded by a MRC programme grant to IJS (G0500366) and a project grant from the Association for International Cancer Research to KAN, RCW and IJS. The HCT116 cells were kindly provided by Prof B Vogelstein (The Howard Hughes Medical Institute and The Johns Hopkins Oncology Center, 424 North Bond Street, Baltimore, MD 21231, USA. )

\section{References}

[1] Li R, Bianchet MA, Talalay P, Amzel LM. The three-dimensional structure of $\mathrm{NAD}(\mathrm{P}) \mathrm{H}:$ quinone reductase, a flavoprotein involved in cancer chemoprotection and chemotherapy: mechanism of the two-electron reduction. Proc Natl Acad Sci USA $1995 ; 92: 8846-50$

[2] Siegel D, Gustafson DL, Dehn DL, Han JY, Boonchoong P, Berliner LJ, et al. NAD(P)H:Quinone Oxidoreductase 1: Role as a Superoxide Scavenger. Molecular Pharmacology 2004;65:1238-47.

[3] Lind C, Cadenas E, Hochstein P, Ernster, L. DT-diaphorase: purification, properties, and function. Methods Enzymol 1990;186:287-301.

[4] Faig M, Bianchet MA, Talalay P, Chen S, Winski S, Ross D, et al. Structures of recombinant human and mouse $\mathrm{NAD}(\mathrm{P}) \mathrm{H}$ :quinone oxidoreductases: species comparison and structural changes with substrate binding and release. Proc Natl Acad Sci USA 2000;97:3177-82. 
[5] Asher G, Reuven N, Shaul Y. 20S proteasomes and protein degradation "by default". Bioessays 2006;28:844-9.

[6] Asher G, Dym O, Tsvetkov P, Adler J, Shaul Y. The crystal structure of NAD(P)H quinone oxidoreductase 1 in complex with its potent inhibitor dicoumarol. Biochemistry 2006; 45:6372-8.

[7] Alard A, Fabre B, Anesia R., Marboeuf C, Pierre P, Susini C, et al. NAD(P)H Quinone-Oxydoreductase 1 Protects Eukaryotic Translation Initiation Factor 4GI. Mol Cell Biol 2010;30:1097-1105.

[8] Asher G, Tsvetkov P, Kahana C, Shaul Y. A mechanism of ubiquitinindependent proteasomal degradation of the tumor suppressors p53 and p73. Genes Dev 2005;19:316-21.

[9] Ernster L, Ljunggren M, Danielson L. Purification and some properties of a highly dicumarol-sensitive liver diaphorase. Biochemical and Biophysical Research Communications 1960;2:88-92.

[10] Ernster L. DT diaphorase. Methods in Enzymology 1967;10:309-17.

[11] Asher G, Lotem J, Cohen B, Sachs L, Shaul Y. Regulation of p53 stability and p53dependent apoptosis by NADH quinone oxidoreductase 1. Proc Natl Acad Sci USA 2001;98:1188-93. 
[12] Tsvetkov P, Reuven N, Shaul Y. Ubiquitin-independent p53 proteasomal degradation. Cell Death Differ 2010;17:103-8.

[13] Schlager JJ, Powis G. Cytosolic NAD(P)H:(quinone-acceptor) oxidoreductase in human normal and tumor tissue: effects of cigarette smoking and alcohol. Int J Cancer $1990 ; 45: 403-9$.

[14] Workman P, Stratford IJ. The experimental development of bioreductive drugs and their role in cancer therapy. Cancer Metastasis Rev 1993;12:73-82.

[15] Workman P. Enzyme-directed bioreductive drug development revisited: a commentary on recent progress and future prospects with emphasis on quinone anticancer agents and quinone metabolizing enzymes, particularly DT-diaphorase. Oncol Res 1994;6:461-75.

[16] Cummings J, Spanswick VJ, Tomasz M, Smyth JF. Enzymology of mitomycin C metabolic activation in tumour tissue: implications for enzyme-directed bioreductive drug development. Biochem Pharmacol 1994;56:405-14.

[17] Robertson N, Stratford IJ, Houlbrook S, Carmichael J, Adams GE. The sensitivity of human tumour cells to quinine bioreductive drugs: what role for DT-diaphorase? Biochem Pharmacol 1992;44:409-12. 
[18] Gustafson DL, Beall HD, Bolton EM, Ross D, Waldren CA. Expression of human $\mathrm{NAD}(\mathrm{P}) \mathrm{H}$ : quinone oxidoreductase (DT-diaphorase) in Chinese hamster ovary cells: effect on the toxicity of antitumor quinones. Mol Pharmacol 1996;50:728-35.

[19] Winski SL, Hargreaves RH, Butler J, Ross D. A new screening system for NAD(P)H:quinone oxidoreductase (NQO1)-directed antitumor quinones: identification of a new aziridinylbenzoquinone, RH1, as a NQO1-directed antitumor agent. Clin Cancer Res 1998;4:3083-8.

[20] Ough M, Lewis A, Bey EA, Gao J, Ritchie JM, Bornmann W et al. Efficacy of betalapachone in pancreatic cancer treatment: exploiting the novel, therapeutic target NQO1. Cancer Biol Ther 2005;4:95-102.

[21] Robertson N, Haigh A, Adams GE, Stratford IJ. Factors affecting sensitivity to EO9 in rodent and human tumour cells in vitro: DT-diaphorase activity and hypoxia. Eur J Cancer 1994;30A:1013-9.

[22] Plumb JA, Gerritsen M, Workman P. DT-diaphorase protects cells from the hypoxic cytotoxicity of indoloquinone EO9. Br J Cancer 1994;70:1136-43.

[23] Asher G, Lotem J, Tsvetkov P, Reiss V, Sachs L, Shaul Y. P53 hot-spot mutants are resistant to ubiquitin-independent degradation by increased binding to NAD(P)H:quinone oxidoreductase 1. Proc Natl Acad Sci U S A 2003;100:15065-70. 
[24] Garten S, Wosilait WD. Comparative study of the binding of coumarin anticoagulants and serum albumins. Biochemical Pharmacology 1971;20:1661-8.

[25] Collier AC, Pritsos CA. The mitochondrial uncoupler dicumarol disrupts the MTT assay. Biochem Pharmacol 2003;66:281-7.

[26] Gonzalez-Aragon D, Ariza J, Villalba JM. Dicoumarol impairs mitochondrial electron transport and pyrimidine biosynthesis in human myeloid leukemia HL-60 cells. Biochem Pharmacol 2007;73:427-39.

[27] Du J, Daniels DH, Asbury C, Venkataraman S, Liu J, Spitz DR, et al. Mitochondrial production of reactive oxygen species mediates dicumarol-induced cytotoxicity in cancer cells. J Biol Chem 2006;281:37416-26.

[28] Nolan KA, Zhao H, Faulder PF, Frenkel AD, Timson DJ, Siegel D, et al. Coumarinbased inhibitors of human $\mathrm{NAD}(\mathrm{P}) \mathrm{H}$ :quinone oxidoreductase-1. Identification, structure-activity, off-target effects and in vitro human pancreatic cancer toxicity. $\mathrm{J}$ Med Chem 2007;50:6316-25.

[29] Lewis A, Ough M, Li L, Hinkhouse MM, Ritchie JM, Spitz DR, et al. Treatment of pancreatic cancer cells with dicumarol induces cytotoxicity and oxidative stress. Clin Cancer Res 2004;10:4550-8.

[30] Cullen JJ, Hinkhouse MM, Grady M, Gaut AW, Liu J, Zhang YP, Weydert CJ,et al. Dicumarol inhibition of NADPH:quinone oxidoreductase induces growth inhibition of 
pancreatic cancer via a superoxide-mediated mechanism. Cancer Res 2003;63:551320.

[31] Reigan P, Colucci MA, Siegel D, Chilloux A, Moody CJ, Ross D. Development of indolequinone mechanism-based inhibitors of $\mathrm{NAD}(\mathrm{P}) \mathrm{H}$ :quinone oxidoreductase 1 (NQO1), NQO1 inhibition and growth inhibitory activity in human pancreatic MIA PaCa-2 cancer cells. Biochemistry 2007;46:5941-50.

[32] Dehn DL, Siegel D, Zafar KS, Reigan P, Swann E, Moody CJ, et al. 5-Methoxy-1,2dimethyl-3-[(4-nitrophenoxy)methyl]-indole-4,7-dione, a mechanism-based inhibitor of $\mathrm{NAD}(\mathrm{P}) \mathrm{H}$ :quinine oxidoreductase 1, exhibits activity against human pancreatic cancer in vitro and in vivo. Mol Cancer Ther 2006;5:1702-9.

[33] Nolan KA, Doncaster JR, Dunstan MS, Scott KA, Frenkel AD, Siegel D, et al. Synthesis and biological evaluation of coumarin-based inhibitors of NAD(P)H: quinone oxidoreductase-1 (NQO1). J Med Chem 2009;52:7142-56.

[34] Nolan KA, Scott KA, Barnes J, Doncaster J, Whitehead RC, Stratford IJ. Phamacological inhibitors of NAD(P)H quinone oxidoreductase, NQO1: Structure/activity relationships and functional activity in tumour cells. Biochem Pharmacol 2010;80:977-81.

[35] Cowen RL, Patterson AV, Telfer BA, Airley RE, Hobbs S, Phillips RM, et al. Viral delivery of P450 reductase recapitulates the ability of constitutive overexpression of 
36] Smith PK, Krohn RI, Hermanson GT, Mallia AK, Gartner FH, et al, Measurement of protein using bicinchoninic acid. Anal. Biochem 1985;150:76-85.

[37] Mosmann T. Rapid colorimetric assay for cellular growth and survival: application to proliferation and cytotoxicity assays. J. Immunol Methods 1983;65:55-63.

[38] Carter WO, Narayanan PK, Robinson JP. Intracellular hydrogen peroxide and superoxide anion detection in endothelial cells. J Leukoc Biol 1994;55:253-8.

[39] Fernandes DC, Wosniak J Jr, Pescatore LA, Bertoline MA, Liberman M, Laurindo FR, et al. Analysis of DHE-derived oxidation products by HPLC in the assessment of superoxide production and NADPH oxidase activity in vascular systems. Am J Physiol Cell Physiol 2007;292:C413-22.

[40] Bello RI, Gomez-Diaz C, Navas P, Villalba JM. NAD(P)H:quinone oxidoreductase 1 expression, hydrogen peroxide levels, and growth phase in HeLa cells. Methods Enzymol 2004;382:234-43.

[41] Anwar A, Siegel D, Kepa JK, Ross D. Interaction of the Molecular Chaperone Hsp70 with Human NAD(P)H:Quinone Oxidoreductase 1. J Biol Chem 2002;277:14060-7. 
[42] Dehn D, Winski SL, Ross D. Development of a New Isogenic Cell-Xenograft System for Evaluation of NAD(P)H:Quinone Oxidoreductase-Directed Antitumor Quinones: Evaluation of the Activity of RH1. Clin Cancer Res 2004;10; 3147-55.

[43] Begleiter A, Leitha MK, Doherty GP, Digby TJ, Pand S. Factors influencing the induction of DT-diaphorase activity by 1,2-dithiole-3-thione in human tumor cell lines. Biochem Pharmacol 2001;61:955-64.

[44] Bunz F, Dutriaux A, Lengauer C, Waldman T, Zhou S, Brown JP, et al. Requirement for p53 and p21 to sustain G2 arrest after DNA damage. Science 1998;282:1497-501.

[45] Kappus H, Sies H. Toxic drug effects associated with oxygen metabolism: redox cycling and lipid peroxidation. Experientia 1981;37:1233-41.

[46] Bello RI, Gơmez-D1'az C, Lo'pez-Lluch G, Forthoffer N, Cớrdoba-Pedregosa A, Pla'cido Navas B, et al. Dicoumarol relieves serum withdrawal-induced G0/1 blockade in HL-60 cells through a superoxide-dependent mechanism. Biochem Pharmacol 2005;69:1613-25.

[47] Ormerod MG, Collins MK, Rodriguez-Tarduchy G, Robertson D. Apoptosis in interleukin-3-dependent haemopoietic cells. Quantification by two flow cytometric methods. J Immunol Methods. 1992;153:57-65. 
[48] Gong X, Kole L, Iskander K, Jaiswal AK. NRH:quinone oxidoreductase 2 and $\mathrm{NAD}(\mathrm{P}) \mathrm{H}$ :quinone oxidoreductase 1 protect tumor suppressor p53 against 20s proteasomal degradation leading to stabilization and activation of p53. Cancer Res 2007;67:5380-8.

[49] Iskander K, Gaikwad A, Paquet M, Long 2nd DJ, Brayton C, Barrios R, et al. Lower induction of p53 and decreased apoptosis in NQO1-null mice lead to increased sensitivity to chemical-induced skin carcinogenesis. Cancer Res 2005;65:2054-8.

[50] Ahn KS, Sethi G, Jain AK, Jaiswal AK, Aggarwal BB. Genetic deletion of $\mathrm{NAD}(\mathrm{P}) \mathrm{H}$ :quinone oxidoreductase 1 abrogates activation of nuclear factor- kappaB, IkappaBalpha kinase, c-Jun N-terminal kinase, Akt, p38, and p44/42 mitogenactivated protein kinases and potentiates apoptosis. J Biol Chem 2006;281:19798-808.

[51] Strom E, Sathe S, Komarov PG, Chernova OB, Pavlovska I, Shyshynova I, et al. Small-molecule inhibitor of p53 binding to mitochondria protects mice from gamma radiation. Nat Chem Biol 2006;2:474-9.

[52] Ghosh SP, Perkins MW, Hieber K, Kulkarni S, Kao TC, Reddy EP. Radiation protection by a new chemical entity, Ex-Rad: efficacy and mechanisms. Radiat Res $2009 ; 171: 173-9$ 


\section{Graphical abstract}

Differential effects of dicoumarol analogues as inhibitors of NQO1, production of superoxide and induction of apoptosis and toxicity in cancer cells.<smiles>[R6]c1c([R6])c([R5])c2c(O)c([X])c(=O)oc2c1[R5]</smiles><smiles>[R6]c1c([R6])c([R5])c2c(O)c(C([X])c3c(O)c4c([R5])c([R6])c([R6])c([R6])c4oc3=O)c(=O)oc2c1[R5]</smiles> 
Table 1. Substituents in the $\mathbf{S}$ and $\mathbf{A S}$ series (Figure 1) together with the concentration of each compound that inhibits the activity of recombinant human NQO1 by $50 \%\left(\mathrm{IC}_{50}\right)$ in the presence of $0.14 \%(w / v)$ BSA [22]. Also given are concentrations of each inhibitor that causes $50 \%$ toxicity in cells in the presence of $1 \mu \mathrm{M}$ EO9. This concentration of EO9 alone will kill $\geq 90 \%$ of the HT29, A549 or MIA PaCa-2 cells; hence the values quoted give a measure of the efficiency of protection against EO9 toxicity [23]. This reflects the ability of the $\mathbf{S}$ and $\mathbf{A S}$ compounds to inhibit NQO1 activity in the cancer cells. Each experiment was repeated on at least three separate occasions and mean values are given \pm standard deviation.

\begin{tabular}{|c|c|c|c|c|c|c|c|c|c|}
\hline \multirow[t]{2}{*}{ ID } & \multirow[t]{2}{*}{ R5 } & \multirow[t]{2}{*}{ R6 } & \multirow[t]{2}{*}{ R7 } & \multirow[t]{2}{*}{$\mathrm{R} 8$} & \multirow[t]{2}{*}{$X$} & \multirow{2}{*}{$\begin{array}{l}\mathrm{IC}_{50}(\mathrm{nM}) \\
\text { With BSA }\end{array}$} & \multicolumn{3}{|c|}{$\begin{array}{c}\text { Concentration needed to protect from } \\
50 \% \text { of EO9 toxicity }(\mu \mathrm{M})\end{array}$} \\
\hline & & & & & & & HT29 & A549 & MIA PaCa-2 \\
\hline S1 & $\mathrm{H}$ & $\mathrm{H}$ & $\mathrm{H}$ & $\mathrm{H}$ & $\mathrm{H}$ & $404 \pm 184$ & $211 \pm 83$ & $118 \pm 5.6$ & $141 \pm 48$ \\
\hline S3 & $\mathrm{OCH}_{3}$ & $\mathrm{H}$ & $\mathrm{H}$ & $\mathrm{H}$ & $\mathrm{H}$ & $38 \pm 2.1$ & $18 \pm 9.0$ & $43 \pm 25$ & $54 \pm 26$ \\
\hline S4 & $\mathrm{H}$ & $\mathrm{OCH}_{3}$ & $\mathrm{H}$ & $\mathrm{H}$ & $\mathrm{H}$ & $3300 \pm 600$ & $>1000$ & $>250$ & $>250$ \\
\hline S5 & $\mathrm{H}$ & $\mathrm{H}$ & $\mathrm{OCH}_{3}$ & $\mathrm{H}$ & $\mathrm{H}$ & $790 \pm 355$ & $875 \pm 211$ & $>250$ & $>250$ \\
\hline S10 & $\mathrm{H}$ & $\mathrm{CH}_{3}$ & $\mathrm{CH}_{3}$ & $\mathrm{H}$ & $\mathrm{H}$ & $233 \pm 68$ & $106 \pm 29$ & $165 \pm 63$ & $158 \pm 72$ \\
\hline S11 & $\mathrm{H}$ & $\mathrm{OCH}_{3}$ & $\mathrm{OCH}_{3}$ & $\mathrm{H}$ & $\mathrm{H}$ & $1497 \pm 442$ & $1954 \pm 940$ & - & - \\
\hline S13 & $\mathrm{H}$ & $\mathrm{H}$ & $\mathrm{CH}_{3}$ & $\mathrm{CH}_{3}$ & $\mathrm{H}$ & $149 \pm 101$ & $132 \pm 9.8$ & $68 \pm 16$ & $109 \pm 21$ \\
\hline AS1 & $\mathrm{H}$ & $\mathrm{CH}_{3}$ & $\mathrm{CH}_{3}$ & $\mathrm{H}$ & 1-naphthyl & $1095 \pm 290$ & $105 \pm 77$ & $251 \pm 78$ & $148 \pm 42$ \\
\hline AS2 & $\mathrm{H}$ & $\mathrm{CH}_{3}$ & $\mathrm{CH}_{3}$ & $\mathrm{H}$ & 2-naphthyl & $167 \pm 83$ & $50 \pm 33$ & $64 \pm 38$ & $89 \pm 27$ \\
\hline AS3 & $\mathrm{H}$ & $\mathrm{CH}_{3}$ & $\mathrm{CH}_{3}$ & $\mathrm{H}$ & phenyl & $660 \pm 108$ & $128 \pm 69$ & $114 \pm 7.2$ & $312 \pm 55$ \\
\hline AS4 & $\mathrm{H}$ & $\mathrm{H}$ & 7,8 & ${ }_{4} \mathrm{H}_{4}$ & 1-naphthyl & $450 \pm 325$ & $58 \pm 26$ & $129 \pm 29$ & $359 \pm 58$ \\
\hline AS5 & $\mathrm{H}$ & $\mathrm{H}$ & 7,8 & ${ }_{4} \mathrm{H}_{4}$ & 2-naphthyl & $225 \pm 151$ & $97 \pm 52$ & $94 \pm 27$ & $132 \pm 56$ \\
\hline AS6 & $\mathrm{H}$ & $\mathrm{H}$ & & ${ }_{4} \mathrm{H}_{4}$ & phenyl & $880 \pm 364$ & $133 \pm 41$ & $>250$ & $205 \pm 10$ \\
\hline AS14 & $\mathrm{H}$ & $\mathrm{CH}_{3}$ & $\mathrm{CH}_{3}$ & $\mathrm{H}$ & 3,4 dimethylbenzyl & $192 \pm 41$ & $62 \pm 19$ & $61 \pm 7.8$ & $114 \pm 2.3$ \\
\hline
\end{tabular}


Table 2. Intracellular NQO1 activity was measured as described in section 2.3. Each measurement was made on lysates prepared on three separate occasions. Values given are means \pm standard deviation.

\begin{tabular}{|cc|}
\hline & NQO1 Activity \\
Cell Line & (nmol cytochrome c reduced / min / mg protein) \\
& \\
\hline HT29 & $1691 \pm 715$ \\
A549 & $3011 \pm 532$ \\
HCT116 WT & $545 \pm 115$ \\
HCT116 BVP p53 $\%$ & $357 \pm 42$ \\
MIA PaCa-2 & $1252 \pm 142$ \\
MDA-MB-231 WT & $40 \pm 28$ \\
MDA-MB-231 DTD & $4171 \pm 816$ \\
MDA-MB-468 WT & $20 \pm 17$ \\
MDA-MB-468 DTD & $4180 \pm 1589$ \\
T47D WT & $141 \pm 33$ \\
T47D DTD & $5284 \pm 1598$ \\
\hline
\end{tabular}


Table 3. Toxicity of compounds in a panel of cell lines with varying NQO1 activity and p53 functionality. Values represent the means and standard deviations of at least three independent experiments.

\begin{tabular}{|cccccccccc|}
\hline & & \multicolumn{7}{c}{ 96 hour IC $\mathbf{5 0}(\boldsymbol{\mu M})$} \\
Compound & MIA & HCT116 & HCT116 & \multicolumn{2}{c|}{ MDA-MB-231 } & \multicolumn{2}{c}{ MDA-MB-468 } & T47D \\
& PaCa-2 & WT & $\mathbf{p 5 3 - / -}$ & WT & DTD & WT & DTD & WT & DTD \\
\hline S1 & $52 \pm 26$ & $19 \pm 13$ & $22 \pm 13$ & $50 \pm 37$ & $67 \pm 31$ & $30 \pm 12$ & $47 \pm 23$ & $51 \pm 6.2$ & $41 \pm 8.3$ \\
S3 & $350 \pm 142$ & $80 \pm 27$ & $58 \pm 33$ & $133 \pm 16$ & $165 \pm 37$ & $174 \pm 45$ & $125 \pm 5.2$ & $98 \pm 52$ & $190 \pm 77$ \\
S4 & $405 \pm 22$ & $48 \pm 1.4$ & $43 \pm 13$ & $77 \pm 7.1$ & $105 \pm 60$ & $58 \pm 22$ & $38 \pm 4.2$ & $283 \pm 46$ & $103 \pm 84$ \\
S5 & $303 \pm 32$ & $187 \pm 17$ & $180 \pm 7.1$ & $202 \pm 82$ & $162 \pm 78$ & $148 \pm 16$ & $155 \pm 35$ & $109 \pm 56$ & $68 \pm 31$ \\
S10 & $106 \pm 33$ & $35 \pm 1.4$ & $33 \pm 5.6$ & $66 \pm 51$ & $41 \pm 2.6$ & $51 \pm 26$ & $56 \pm 30$ & $66 \pm 47$ & $45 \pm 16$ \\
S11 & $>400$ & $>400$ & $>400$ & $>400$ & $>400$ & $>400$ & $>400$ & $>400$ & $>400$ \\
S13 & $119 \pm 42$ & $35 \pm 16$ & $41 \pm 13$ & $114 \pm 36$ & $173 \pm 15$ & $123 \pm 31$ & $141 \pm 22$ & $111 \pm 38$ & $103 \pm 32$ \\
\hline AS1 & $188 \pm 2.9$ & $56 \pm 4.9$ & $76 \pm 48$ & $32 \pm 9.0$ & $51 \pm 64$ & $107 \pm 17$ & $45 \pm 29$ & $124 \pm 67$ & $116 \pm 71$ \\
AS2 & $162 \pm 28$ & $180 \pm 21$ & $165 \pm 44$ & $119 \pm 48$ & $115 \pm 59$ & $142 \pm 68$ & $75 \pm 51$ & $143 \pm 57$ & $95 \pm 74$ \\
AS3 & $267 \pm 31$ & $178 \pm 2.8$ & $122 \pm 65$ & $102 \pm 70$ & $185 \pm 18$ & $231 \pm 70$ & $99 \pm 46$ & $145 \pm 42$ & $117 \pm 69$ \\
AS4 & $163 \pm 20$ & $102 \pm 18$ & $111 \pm 21$ & $41 \pm 5.2$ & $60 \pm 58$ & $100 \pm 21$ & $67 \pm 41$ & $94 \pm 22$ & $88 \pm 29$ \\
AS5 & $152 \pm 16$ & $39 \pm 2.8$ & $31 \pm 4.7$ & $41 \pm 15$ & $58 \pm 15$ & $102 \pm 22$ & $58 \pm 34$ & $58 \pm 36$ & $51 \pm 17$ \\
AS6 & $222 \pm 60$ & $40 \pm 45$ & $68 \pm 48$ & $124 \pm 40$ & $94 \pm 21$ & $173 \pm 27$ & $100 \pm 36$ & $13 \pm 61$ & $89 \pm 16$ \\
AS14 & $407 \pm 15$ & $176 \pm 6.4$ & $172 \pm 43$ & $152 \pm 36$ & $164 \pm 25$ & $248 \pm 37$ & $154 \pm 21$ & $170 \pm 7.0$ & $138 \pm 3.5$ \\
\hline
\end{tabular}




\section{Figure captions}

Figure 1. Structures of substituted 4-hydroxycoumarins (AS series) and analogues of dicoumarol ( $\mathbf{S}$ series). Substituents $\mathrm{R}_{5}-\mathrm{R}_{8}$ and $\mathrm{X}$ are given in Table 1.

Figure 2. Dose-dependent increase of intracellular superoxide following treatment of MIA PaCa-2 cells with dicoumarol for 4 hours: A; Background fluorescence intensity in control cells. B -D; Fluorescence intensity in cells treated with 100, 200 and $400 \mu \mathrm{M}$ dicoumarol (S1) respectively. E; Exposure of cells to $50 \mu \mathrm{M}$ menadione. F; Exposure of cells to $200 \mu \mathrm{M}$ dicoumarol plus $500 \mu \mathrm{M}$ ambroxol. Histograms are representative images of experiments performed on at least three independent occasions.

Figure 3. Superoxide production in MIA PaCa-2 cells treated for 4 hours with increasing concentrations of dicoumarol (S1) and the other $\mathbf{S}$ and $\mathbf{A S}$ compounds. Menadione $(50 \mu \mathrm{M})$ and DMSO vehicle controls were carried out in each experiment. Bars represent mean and standard deviation of at least three independent experiments.

Figure 4. The relationship between superoxide production and toxicity in the MIA PaCa-2 cell line, $\mathbf{A S}$ compounds $=\bullet ; \mathbf{S}$ compounds $=\circ$; dicoumarol $=\mathbf{S 1}$.

Figure 5. Intracellular superoxide production is independent of the activity of NQO1 in MDA-MB-231 cells: Cells were treated for 4 hours with 100 $\mu \mathrm{M}$ of dicoumarol (S1) and the other $\mathbf{S}$ or $\mathbf{A S}$ compounds. Each measurement was made on three separate occasions and values are given \pm standard deviation. (Black bars $=$ WT cells; White bars $=$ DTD cells). 
Figure 6. Representative DNA histograms displaying cell distributions following 24 hour treatment with $200 \mu \mathrm{M}$ dicoumarol (S1), S3 or AS2: The percentage of cells in the different phases of the cell cycle for all the compounds are given in the Supplementary data, Table 1 . Cell cycle profiles were generated on at least three independent occasions.

Figure 7. The percentage of cells in the sub-G1 region of the cell cycle compared with measurement of cleaved PARP by Western blot: MIA PaCa- 2 cells were treated for 24 hours with vehicle or $200 \mu \mathrm{M}$ of dicoumarol (S1) or the other $\mathbf{S}$ or $\mathbf{A S}$ compounds then either stained with PI for cell cycle analysis or cell lysates prepared for assessment of cleaved PARP. The values of the percentage of cells within the subG1 region were obtained from at least three independent experiments ( \pm standard deviation), the asterisks give the significance from the controls in each experiment ${ }^{*}$ $=\mathrm{p} \leq 0.05, * *=\mathrm{p} \leq 0.01)$. The Western blot is a representative from three separate experiments. 
Figure 1.<smiles>[R5]c1c([R6])c([R6])c2c(O)c([X])c(=O)oc2c1[2H]</smiles>

AS

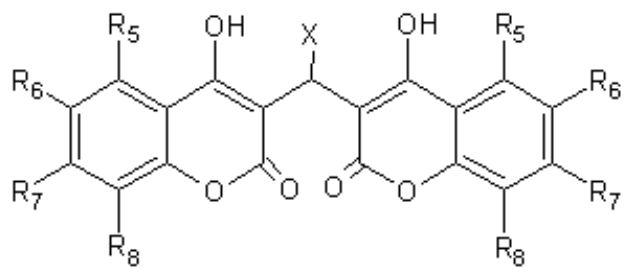

S 
Figure 2.

Figure 3.
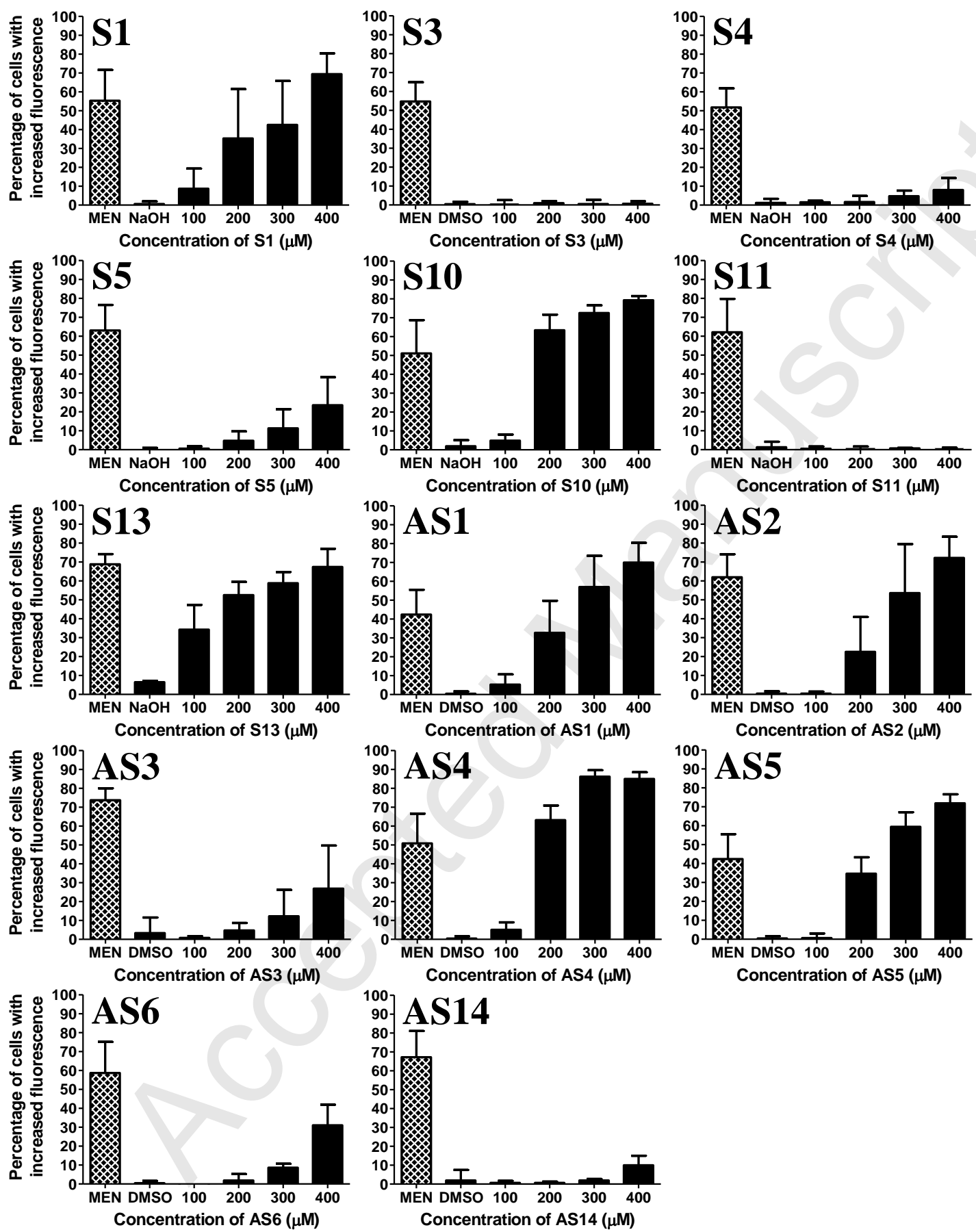
Figure 4.

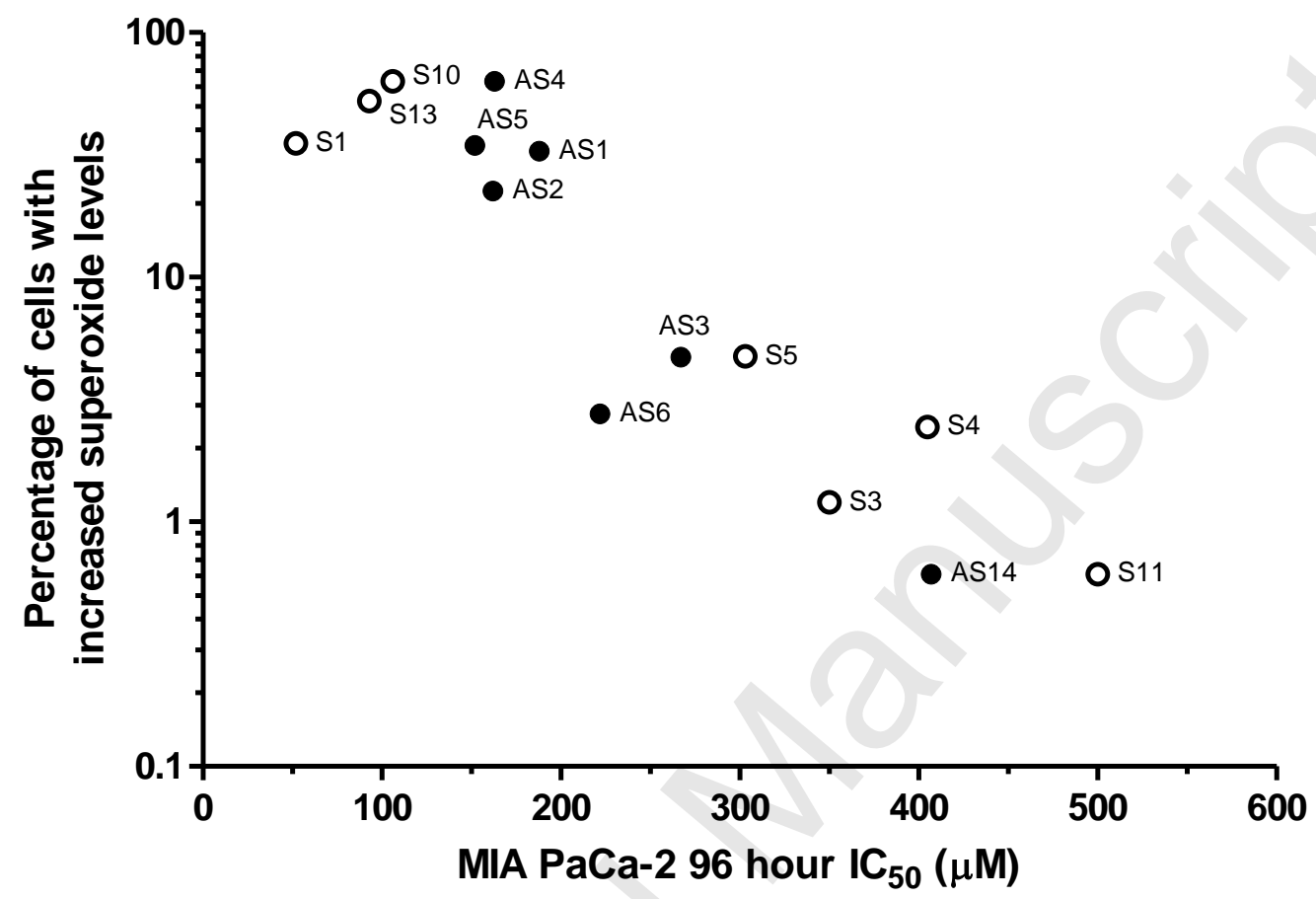


Figure 5.

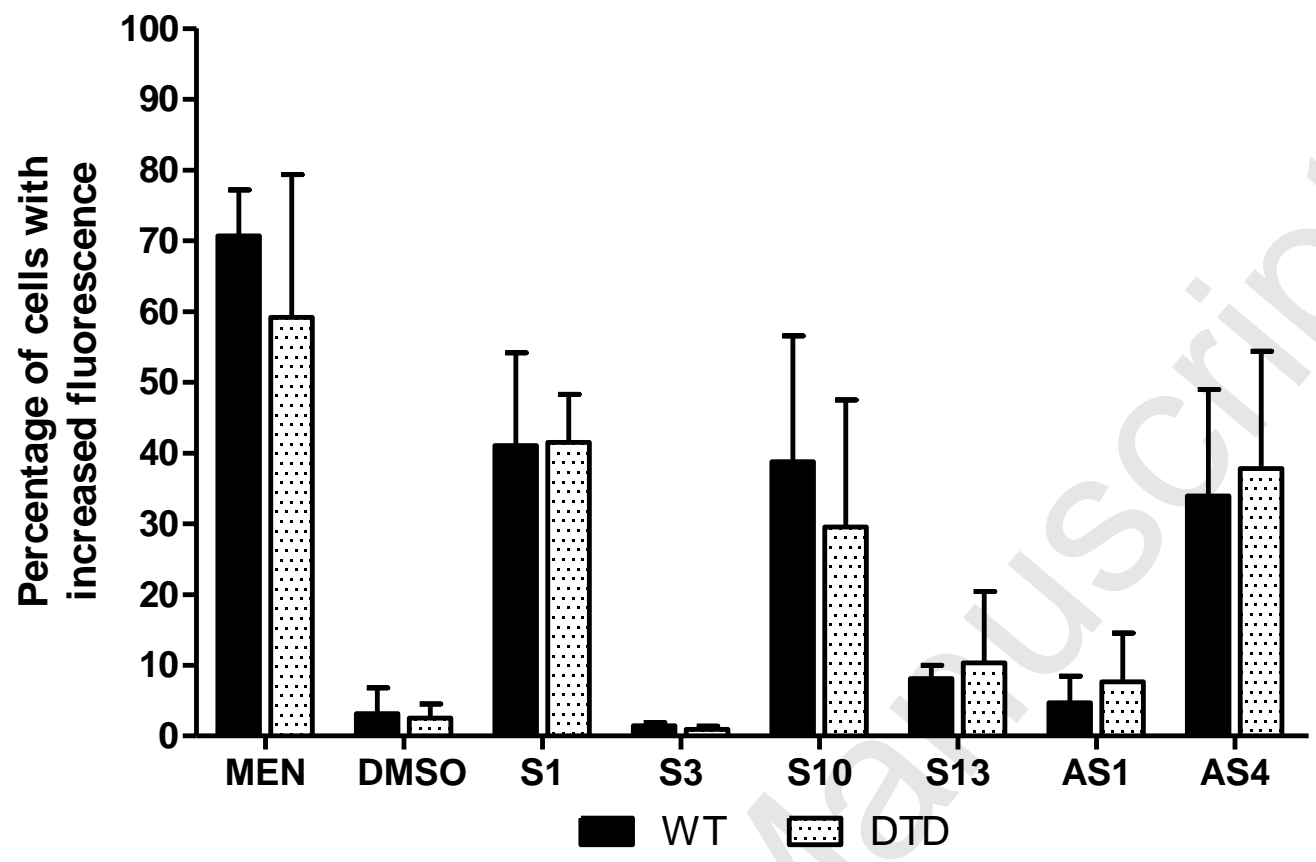


Figure 6.

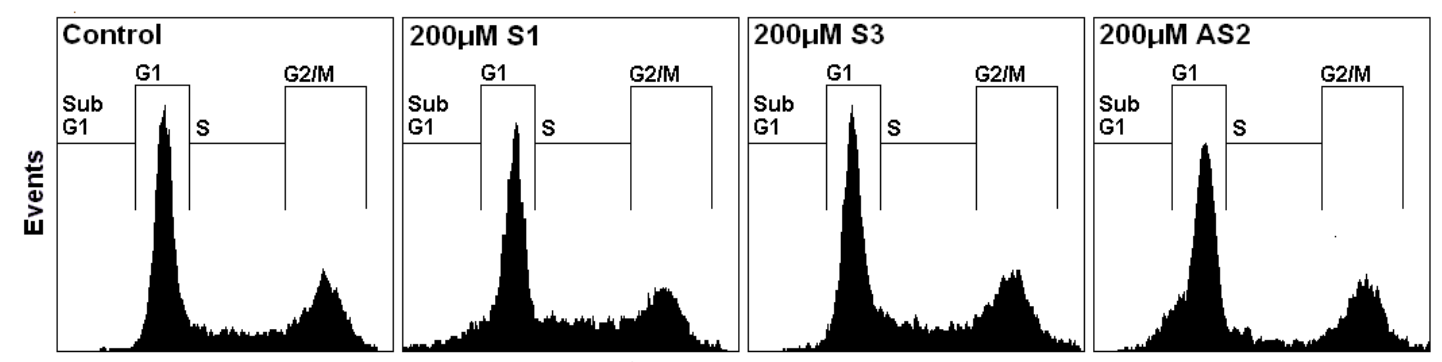

Fluorescence Intensity 
Figure 7.

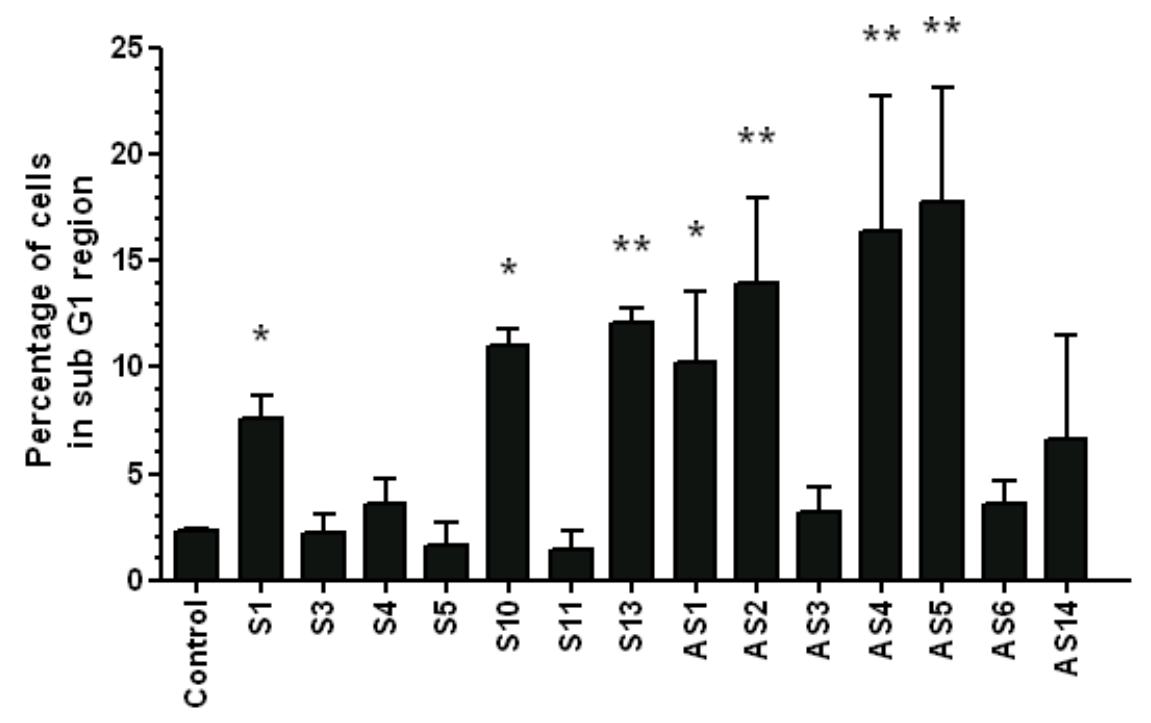

Cleaved

PARP

Actin 